International Journal of Current Advanced Research

ISSN: O: 2319-6475, ISSN: P: 2319 - 6505, Impact Factor: SJIF: 5.995

Available Online at www.journalijcar.org

Volume 6; Issue 5; May 2017; Page No. 3638-3640

DOI: http://dx.doi.org/10.24327/ijcar.2017.3640.0336

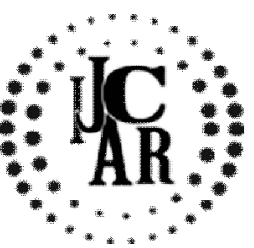

Case Report

\title{
SATISFACTION LEVEL OF PATIENTS, POST DENTAL IMPLANT TREATMENT
}

\author{
Reshma HK*., Preetham Prasad and Dhanraj
}

Department of Prosthodontics, Saveetha Dental College

\section{\begin{tabular}{llll}
\hline A R T I C L E & I N F O
\end{tabular}}

Article History:

Received $7^{\text {th }}$ February, 2017

Received in revised form $12^{\text {th }}$ March, 2017

Accepted $15^{\text {th }}$ April, 2017

Published online $28^{\text {th }}$ May, 2017

Key words:

Post Dental Implant

\begin{abstract}
A B S T R A C T
Aim: To evaluate the satisfaction level of patients, two years after post dental implant therapy.

Objective: Knowledge regarding patient's satisfaction will help motivate other patients to undergo dental implant therapy. This will also encourage them to undergo the treatment without the stress or anxiety which others might have. Understanding the patients satisfaction level will help the dentist understand the patients point of view and help improve on his/her methods.

Materials and Method: a total of 50 patients, who had undergone dental implant therapy about two years ago were evaluated. They were all given questionnaires to fill up based on Bjarni E. Pjeturrsson's article that was published in the year 2004.

Result: From the study that was conducted, we concluded that about $98 \%$ of the patients were satisfied with dental implant treatment. $88 \%$ of the patients were able to chew properly using their crown. $86 \%$ were satisfied with the phonetics and $88 \%$ for the aesthetics of the implant placed. $80 \%$ were able to clean their implants without any difficulty.

Conclusion: It was concluded from the study conducted, that most of the patients were satisfied with the treatment they received. It was also noted that more percentage of females were esthetically concerned.
\end{abstract}

Copyright $\odot 2017$ Reshma HK et al. This is an open access article distributed under the Creative Commons Attribution License, which permits unrestricted use, distribution, and reproduction in any medium, provided the original work is properly cited.

\section{INTRODUCTION}

Dental Implants refer to an artificialmaterialthat is embedded into a patients maxilla or mandiblethat replaces the missing natural tooth/ teeth.[1] This treatment could be an option for those patients who have lost their tooth/teeth due to diseases, trauma or other reasons. They provide proper treatment with reliable success rates in the past. Dental implants are usually made up of titanium, however many other newer materials have been introduced over the last decade.[2-4]When it is placed in the jawbone and fuses, or integrates with the bone through the process of osseointegration[5], thereby forming stable and sturdy base for the lost tooth.[6] This treatment is an option for those individuals who have lost their tooth/ teeth due to diseases, trauma or other reasons.[7]

There are three main types of dental implants, they are: Endosteal Implants, Subperiosteal Implants and Transosseous Implants. Endosteal implants are those implants that are surgically placed in the jawbone, as a substitute to the root. They are the most commonly used dental implants these days.[8] Subperiosteal implants are placed under the gum, on or above the jaw bone. This type of dental implant can be used for patients that have a shallow jaw bone.

*Corresponding author: Reshma HK

Department of Prosthodontics, Saveetha Dental College
They are more expensive compared to endosteal implants as they have to be custom made for each patient according to the impression taken. Transosseous implants are the type of implants, only to be used for the lower jaw. This type of implant is not that commonly used these days due to extensive surgery, anesthesia and hospitalization that would follow. The surgery would involve inserting two metal rods from below the chin, through the jaw bone till they are exposed in the mouth where they are used to attach the denture. The dental implants have been used successfully used over the past few decades and have shown optimum success rates 95.5\% [9-12]

Implants are available in various materials, shapes and surface features.[13] It has been estimated that dentists have to choose from more than 1300 types of implants that vary in form, material, dimension, surface properties and interface geometry.[8]

Modern dental implants have been used since the 1970s and since then, have undergone many improvements in design and they have also improved on their aesthetic values. The earliest forms of dental implants were recorded to have been used by the Mayan Civilization dating back to 600 AD. Materials ranging from carved stones to fragments of sea shells were used. The advancements in this field were really seen in the year 1952, when titanium was used as the material. They were first used on patients who had lost all their teeth and for those 
who had difficulties dealing with dentures. Modern implants come in various shapes and sizes to replace the missing teeth. The success rates of implant procedures would include: biocompatibility of the implant material, nature of the implant surface, bone quality the surgical technique used, the healing phase the subsequent prosthetic phase, design, material used, location of the implant and hygienic and cosmetic conditions.[12, 14] In other studies, the success rate of dental implant treatments are roughly seen to be $95 \%$. The problems that do arise are minor and can be rectified easily. The problems that usually rise from implant treatments include infection at the site, injury or damage to the surrounding structures and soft tissues, nerve damage that will cause pain or numbness. Sinus problems can also take place when dental implants are placed in the upper jaw and they protrude into one of the sinus cavities.

Feedbacks from the patients regarding the treatment have helped doctors improve upon their techniques. Hence, this study was conducted to evaluate the satisfaction level of patients, two years after post dental implant therapy. Studies such as this would help motivate other patients to undergo the treatment without stress or anxiety.

\section{MATERIALS AND METHODS}

The study was done by giving out questionnaires to about 40 patients who had undergone dental implant therapy about two years back, in Saveetha Dental College. The questionnaire was based on the one in Bjarni E. Pjeturrsson's article that was published in the year 2004 .

The patients were asked to evaluate 6 statements regarding function and chewing comforts, phonetics, aesthetics, oral hygiene practices, general satisfaction and cost. A five grade categorizing scale: 'Very Satisfied', to 'not at all satisfied' was used.

The questions included in the patient survey are showed in figure no. 1

\begin{tabular}{|c|c|}
\hline $\begin{array}{l}\text { Name: } \\
\text { Age: } \\
\text { OP no. } \\
\text { Age of Restoration: }\end{array}$ & aire \\
\hline Questions & \\
\hline 1) My cown/ bridge functions ves well and I can ohew on it very well & 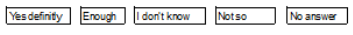 \\
\hline 2) To speak, I can very well uss e my cown/ bridge & 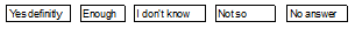 \\
\hline 3) I Im pleas ed with the gesthetic results & 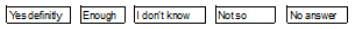 \\
\hline 4) I can dean my implant very well & 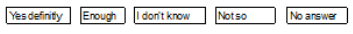 \\
\hline 5) It is eas ier for me to dean my implants than to dean my teeth & Ees definity Enough loorit know Notso \\
\hline 6) I got exsadty what l expected & 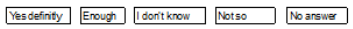 \\
\hline
\end{tabular}

1. My crown/bridge functions very well and I can chew on it very well.

2. To speak, I can very well use my crown/ bridge.

3. I'm pleased with the aesthetic results.

4. I can clean my implant very well.

5. It is easier to clean my implant than to clean my teeth.

6. I got exactly what I expected

\section{RESULTS}

Out of the 40 patients that were chosen for the survey, 25 were males and 15 were females. The mean age for male was calculated to be $41.6( \pm 14.106)$ and for female was 40.667 $( \pm 12.499)$.

The cumulative data compiled from the questionnaire has been shown in figure 2

The satisfactory level of patients regarding their chewing function, speech, aesthetics, cleanliness and expectations are shown in figures 3 . Out of the $98 \%$ who were very satisfied, $72 \%$ were males and $27 \%$ were females.

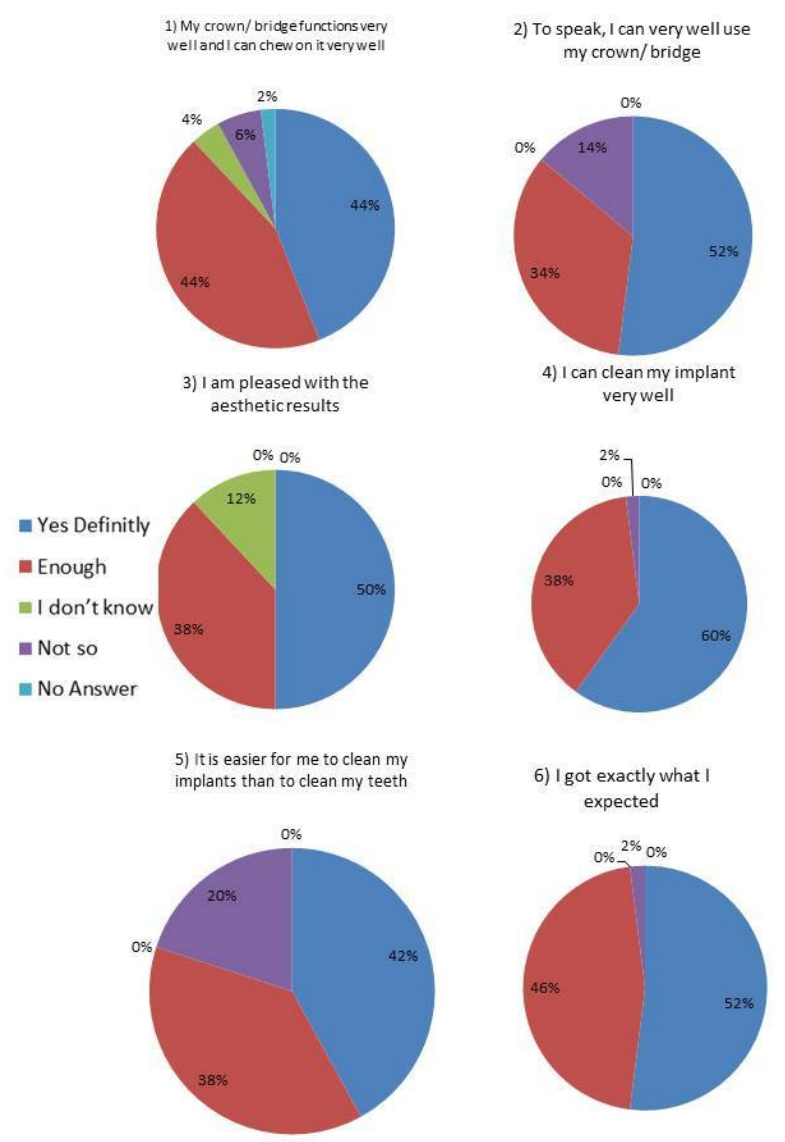

\section{DISCUSSION}

Presently, there are many patients who opt for dental implant treatmentand the knowledge about the patient satisfaction and their expectations help in better understanding by the practitioners and to formulate an accurate treatment plan. It has been reported in studies that the success rates of implant fixtures over the observational period of 5 years after placement has been $81 \%$ for maxillary implants and $91 \%$ for mandibular implants. [1] according to the systematic reviews by Jung et al [11] and Pjetursson BE et al [10], the 5 and 10 year survival rates for implants are $94.5 \%$ and $90 \%$ respectively.

\begin{tabular}{|c|c|c|c|c|c|}
\hline Questions & $\begin{array}{c}\text { Yes } \\
\text { Definitely }\end{array}$ & Enough & $\begin{array}{l}\text { I don't } \\
\text { know }\end{array}$ & Not so & $\begin{array}{c}\text { No } \\
\text { Answer }\end{array}$ \\
\hline 1) My crown/ bridge functions very well and I can chew on it very well & 22 & 22 & 2 & 3 & 1 \\
\hline 2) To speak, I can very well use my crown/ bridge & 26 & 17 & 0 & 7 & 0 \\
\hline 3) I am pleased with the aesthetic results & 25 & 19 & 6 & 0 & 0 \\
\hline 4) I can clean my implant very well & 30 & 19 & 0 & 1 & 0 \\
\hline 5) It is easier for me to clean my implants than to clean my teeth & 21 & 19 & 0 & 10 & 0 \\
\hline 6) I got exactly what I expected & 26 & 23 & 0 & 1 & 0 \\
\hline
\end{tabular}


The results of this study reveal that patients find it easier to eat $(44 \%)$ with their implants than before. As they are fixed treatment alternative and can last many years, they are more acceptable by the patients. The results are comparable with that of Pjetursson's study in 2004 where about 97\% of the participated individuals were very satisfied.

Most of the patients surveyed in this study were very satisfied or satisfied with their aesthetics (49\%) and found it very easy to clean their implants as well. (49\%). This was also comparable to Pjetursson's study where $97 \%$ of patients were satisfied with esthetics and $93 \%$ found it convenient to clean the implant site.

About $37 \%$ patients found it easier to clean the implants compared to teeth in Pjetursson's survey whereas $21 \%$ found it easier in this survey.

Most of the patients were satisfied with the overall treatment they received (98\%), and were willing to undergo the treatment again if requiredPjetursson's study revealed $94 \%$ as completely satisfied with their treatments.

The patients who were followed up in this survey had implants placed about 2 years ago. However this may not have influenced the results as Pjetursson's study had a 10 year follow up and the results were comparable nonetheless. This may be attributed to the longevity and the durability that the dental implant treatment provides.

There were comparatively more males in this survey conducted compared to the females.72\% were males and $27 \%$ were females. ThisVallittu et al [15] reported a survey, concluding that appearance was more important to women and younger patients, than men and older ones. However there is no evidence to confirm the same. Chang et al [16] conducted a survey, where the patients were asked to mark their assessment on a 100-mm line having end phrases "not at all satisfied" on the left and "completely satisfied" on the right. The subjects' overall satisfaction was reported as a percentage was 94\%. Avivi-Arber and Zarb [17] used a questionnaire to evaluate the esthetic outcome and reported that $88 \%$ of their patients were satisfied. Carlson et al [18] examined patient satisfaction using a questionnaire, which was administered during patient recalls and reported that $83 \%$ expressed satisfaction with their implant prostheses. All the above studies have shown a close range of percentage satisfaction and hence we cannot conclude that the gender of the patient could've influenced this study.

This study evaluated a low sample size of only 40 patients. However, after comparisons, it has been observed that the percentage of patients that were satisfied with the treatment were more or less similar. As compared to Pjetursson's study that had 104 patients that had a satisfaction level of $97 \%$, it is seen that the study conducted is also reliable as the satisfaction level of patients in it was $98 \%$. From this we can conclude that the sample size is not a factor that could effect the results.

From the survey done, we found out that about $98 \%$ of the patients stated that their implants functioned properly. They were able to chew properly with it and it didn't cause any sort of discomforts. $86 \%$ of the patents were able to speak properly with their implants. They were also able to clean their implants properly and were overall satisfied with the treatment they got.
Most of the patients who undergo this treatment find the cost to have been reasonable. Studies show that about $3 \%$ of the patents state otherwise. [10]

\section{CONCLUSION}

From the study that was conducted, we concluded that about 98\% of the patients were satisfied with dental implant treatment. From this we can clearly see that this treatment is reliable and cost efficient. The results were determined with the help of qualified questions and a follow up of about 1-2 years.

\section{Reference}

1. Pye, A., et al., A review of dental implants and infection. Journal of Hospital infection, 2009. 72(2): p. 104-110.

2. Saini, M., et al., Implant biomaterials: A comprehensive review. World Journal of Clinical Cases: WJCC, 2015. 3(1): p. 52.

3. Andersen, E., H.R. Haanæs, and B.M. Knutsen, Immediate loading of single-tooth ITI implants in the anterior maxilla: a prospective 5-year pilot study. Clinical Oral Implants Research, 2002. 13(3): p. 281-287.

4. Le Guéhennec, L., et al., Surface treatments of titanium dental implants for rapid osseointegration. Dental materials, 2007. 23(7): p. 844-854.

5. Javed, F., et al., Role of primary stability for successful osseointegration of dental implants: factors of influence and evaluation. Interventional Medicine and Applied Science, 2013. 5(4): p. 162-167.

6. Del Fabbro, M., et al., Systematic review of survival rates for implants placed in the grafted maxillary sinus. The Journal of Prosthetic Dentistry, 2005. 94(3): p. 266.

7. Tirachaimongkol, C., et al., Relation between the stability of dental implants and two biological markers during the healing period: a prospective clinical study. International Journal of Implant Dentistry, 2016. 2(1): p. 27.

8. Binon, P.P., Implants and components: entering the new millennium. The International journal of oral \& maxillofacial implants, 2000. 15(1): p. 76.

9. Setzer, F. and S. Kim, Comparison of long-term survival of implants and endodontically treated teeth. Journal of dental research, 2014. 93(1): p. 19-26.

10. Pjetursson, B.E., et al., Patients' satisfaction following implant therapy. Clinical oral implants research, 2005. 16(2): p. 185193.

11. Jung, R.E., et al., A systematic review of the 5-year survival and complication rates of implant-supported single crowns. Clinical oral implants research, 2008. 19(2): p. 119-130.

12. Albrektsson, T., et al., The long-term efficacy of currently used dental implants: a review and proposed criteria of success. Int J Oral Maxillofac Implants, 1986. 1(1): p. 11-25.

13. Esposito, M., et al., Interventions for replacing missing teeth: different types of dental implants. The Cochrane Library, 2007.

14. Vehemente, V.A., et al., Risk factors affecting dental implant survival. Journal of Oral Implantology, 2002. 28(2): p. 74-81.

15. Vallittu, P., A. Vallittu, and V. Lassila, Dental aesthetics-a survey of attitudes in different groups of patients. Journal of Dentistry, 1996. 24(5): p. 335-338.

16. Chang, M., J.L. Wennström, and B. Andersson, Esthetic outcome of implant-supported single-tooth replacements assessed by the patient and by prosthodontists. International Journal of Prosthodontics, 1999. 12(4).

17. Avivi-Arber, L. and G.A. Zarb, Clinical effectiveness of implantsupported single-tooth replacement: the Toronto Study. International Journal of Oral \& Maxillofacial Implants, 1996. 11(3).

18. Carlsson, B. and G.E. Carlsson, Prosthodontic complications in osseointegrated dental implant treatment. International Journal of Oral \& Maxillofacial Implants, 1994. 9(1). 